\title{
IP licensing: how to structure a good deal
}

\author{
FRANCESCO BALDI LENOS TRIGEORGIs*
}

\begin{abstract}
Purpose of the study: How to best structure an IP licensing agreement taking account of embedded optionalities and other terms negotiated between licensor and licensee via a case study involving a prototypical options-based business model (biotech industry).

Methodology: Binomial lattice simulation.

Findings: It shows how IP management practices would change depending on who pays for the development costs, controls the continuation/development or abandonment option and thereby appropriates most of the embedded option's value. It presents alternative (iso-value) menu licensing term choices (different combinations of royalty vs. fixed upfront fee or milestone payments) that are fair and optimal in properly accounting for the optionality embedded in $R \& D$ development and related licensing structures.

Research limits: An extension of our study lies in the collection of a dataset of remuneration structures of (market-based) licensing transactions in the biotechpharmaceutical industry so as to empirically validate our pricing technique.

Practical implications: Real options thinking leads to different perspectives on how patent licensing agreements should be structured properly accounting for which party controls the embedded optionality.

Originality of the paper: It proposes a comprehensive real options approach to: (a) appraise the IP asset capturing the value of optionality embedded in the underlying drug $R \& D$ program; (b) consider licensor and licensee perspectives in negotiating the terms of the IP licensing agreement, providing guidelines on how to determine its optimal remuneration structure reflecting a fair sharing of project value and embedded optionality among the parties; (c) offer a tool for IP portfolio management that helps a licensor prioritize internal $R \& D$ projects accounting for managerial flexibility and optimal licensing design under uncertainty.
\end{abstract}

Key words: licensing; drug development; real options

\footnotetext{
Adjunct Professor of Corporate Finance - LUISS Guido Carli University e-mail: fbaldi@luiss.it

** The Bank of Cyprus Chair Professor of Finance - University of Cyprus e-mail: lenos@ucy.ac.cy
} 


\section{Introduction}

Licensing has become a common tool for managing and leveraging IP assets beyond organizational boundaries (Arora and Fosfuri, 2003; Chesbrough, 2003; Arora and Ceccagnoli, 2006) ${ }^{1}$. In particular, licensing has spread out in the biopharmaceutical industry as a way to conduct research and development (R\&D) activities beyond organizational boundaries via exchange of patented (or patentable) results. In 2008, the potential value of licensing-based strategic alliances involving US biotechnology and pharmaceutical firms reached the record level of $\$ 30$ billion, being mostly driven by biotech-biotech deals, and the European market, after a steady growth in prior years, was worth almost half the one in US (\$13 billion) (Ernst \& Young, 2009). Yet, if compared to many other industrial sectors, the biopharmaceutical industry has been late in outsourcing $R \& D$, with the main reasons being (a) the lack of confidence in partnering and (b) the fear of losing control over the innovation process. At the same time, high and sustainable levels of corporate profitability have ended up not exerting enough financial pressure to implement cost reduction and encourage the outsourcing of parts of non-strategic operations.

Two key factors have contributed to propel the diffusion of licensing activity in the bio-pharmaceutical industry. First, pharmaceutical firms have experienced a huge decline in R\&D productivity over the last decade (with rises in R\&D expenses being converted into less and less marketable products), which have driven them to pursue an outsourcing strategy looking at external services provided by third parties to bring a drug through the various stages of its development (discovery, preclinical, and clinical testing). As a result, as many large pharmaceutical companies struggle to fill their product pipelines, they increasingly leverage their relationships with smaller biotechnology firms to ask for the provision of innovative and novel therapeutic approaches rather than relying on their in-house R\&D capabilities. This allows pharmaceutical firms to focus and further strengthen their core business operations (e.g., manufacturing, distribution, marketing and sales). Second, the cost of drug development has increased due to (i) the need for sophisticated and dedicated production facilities required by the new generation of biochemical pharmaceuticals, (ii) a tightening in the existing regulation, (iii) the call for huge marketing efforts and investments to launch new products on a worldwide basis. Such changes to the industry structure prevent biotechnology companies from manufacturing and distributing their novel compounds internally and prompt them to offer licensing-in opportunities to pharmaceutical players.

1 Taylor and Silbertson (1973) and Caves, Crookell and Killing (1983) provide the very first evidence on the diffusion of licensing agreements across different industries in the U.S., Canada and the UK. Granstrand (1999) defines the notion of license as " $a$ permission granted by an IPR holder, the licensor, to another legal entity (person or company), the licensee, to make use of, sell or otherwise benefit from the underlying IPR under certain restrictive conditions". 
The following statistics clearly reveal the above mentioned industry trends about the growing impact of licensing transactions. 38\% of the 691 new chemical compounds approved by the FDA between 1963 and 1999 were licensed-in (DiMasi, 2001). In 2000, all of Bristol-Myer Squibb's blockbluster products were the result of licensing-in activity (MedAd News, 2000). In 2001, 9 of the top 10 pharmaceutical companies licensed-in more than $40 \%$ of their newly marketed molecular entities, consisting mostly of compounds in Clinical Phases I and II (Cap Gemini Ernst \& Young, 2001). Indeed, in 2001 GlaxoSmithKline licensed-in 9 compounds, and in 2002 Merck reviewed thousands of licensing opportunities completing 32 deals (Drug Week, 2003). In 2005, the global R\&D was expected to grow approximately $5 \%$ per year in the next five years and the outsourced part to grow twice as rapidly $(+10,7 \%)$, accounting for $35 \%$ of the total R\&D market in 2010 (€ 26 billion) (Societé General Equity Research, 2005).

This article deals with how to best structure an IP licensing agreement taking account of embedded optionalities and other terms negotiated between licensor (LR) and licensee (LE), presented in the context of an illustrative case study involving a French biotech, Cerep. The case study highlights the practical relevance in structuring a licensing deal of an options-based business model and related IP management practices. There are two main contributions: (1) illustrating the use of real options logic and methodology to value actual licensing situations for IP managers and (2) examining how perspectives and negotiation practices between LR and LE of IP change under uncertainty in light of real options theory. Our article uses the Cerep company context to show how IP management practices could change depending on who pays for the development costs, controls the continuation/development or abandonment option and thereby appropriates most of the embedded option's value. It presents alternative (iso-value) menu licensing term choices (different combinations of royalty vs. fixed upfront fee or milestone payments) that are fair and optimal in properly accounting for the optionality embedded in the $\mathrm{R} \& \mathrm{D}$ development and related licensing structures.

\section{Licensing valuation and structuring challenges}

Licensing agreements in the bio-pharmaceutical industry are technology-based transactions allowing for the exchange of patented (or patentable) $R \& D$ results with no previous business history (Razgaitis, 2003). They serve as a risk-sharing mechanism enabling parties to split the risks associated with R\&D operations and exploit their respective comparative advantages. Technical risks deriving from the execution of advanced drug development are transferred from the licensee to the licensor. Marketing and commercialization risks are allocated to the licensee, with the licensor no longer being involved in the activities of advertising, distributing and selling the drug subject to the licensing agreement. 
Accurate valuation of all opportunities embodied in a licensing agreement is important for conducting an effective negotiation between the parties. ${ }^{2}$ Appraisal and negotiation are made even more difficult by the complexity of the remuneration structure used in industry transactions (Anand and Khanna, 2000; Bessy et al., 2004). More specifically, licensing contracts studied in the management literature have evolved from contracts specifying a single element, either a fee or royalty rate (Katz and Shapiro, 1985; 1986) through two-part tariff contracts (Shapiro, 1985; Macho-Stadler et al., 1996; Jensen and Thursby, 2001), to contracts with more elements (Thursby et al., 2005). It has been demonstrated that a three-part tariff contract structure with a milestone payment is superior to the generally studied twopart tariff (Crama et al., 2008). A three-part tariff licensing contract structure is thus commonly applied in practice (Hall, 1991; Elfenbein, 2007). Typically, the licensee (pharmaceutical firm) acquires access to the IP rights in exchange for making a series of fixed (upfront fee, milestones) and use-based (royalty) payments to the licensor (biotech firm) as compensation for drug development (Layne-Farrar and Lerner, 2006). Licensing agreements contain a down payment upon the signature of the contract (upfront fee) (Kamien and Tauman, 1984, 1986; Kamien, et al. 1992), lump-sum payments on successful completion of specific milestones (milestone payments) ${ }^{3}$, and regular scheduled payments tied to future drug sales or other measures of performance for the technology being licensed (royalties) (Katz and Shapiro, 1985; Gallini and Wright, 1990; Beggs, 1992; Bousquet et al. 1998; Hernandez-Murillo and Llobet, 2003; Jensen and Thursby, 2001; Thursby et al.,2005). However, remuneration structures may significantly vary in the industry practice. Several types of licensing deals result from different combinations of fixed and use-based payments. One can have the licensing-based alliance between Genzyme and ISIS (both biotechnology companies based in US) that included the largest up-front payment of 2008 (an upfront fee worth \$ 325 million paid for licensing technology and acquiring an equity stake), or the Celgene's transaction with the privately-held Acceleron Pharmaceuticals, which was tending more toward future milestones.

2 Some models have been developed for valuing licensing deals and facilitating negotiations. Ruback and Krieger (2000) propose a decision analysis model to appraise a licensing contract without accounting for the entire problem solving process (from data collection to model design and implementation, including negotiation support). Crama, et al. (2007) develop a valuation model using NPV, decision analysis and Monte Carlo simulation to assess the value of an $R \& D$ project carried out by a biotech company providing insights into the most appropriate licensing contractual structures and hints for negotiations.

3 Thursby et al. (2005) suggest that milestone payments should complement royalties to allow a risk-averse licensor to hedge herself against the risk of successfully completing a technology that has no commercialization potential. Both milestone payments and royalties (Macho-Stadler et al., 1996) ensure that the licensor cooperates with the licensee in developing the licensed technology, thus helping to prevent the former's defection in early-stage technology licensing. 
Deals also differ according to the degree of collaboration between licensor and licensee in (co)developing the candidate drug. In Europe, the 2008 top transaction (based on value potential) was the strategic alliance between GlaxoSmithKline and Actelion, through which the former acquired the worldwide rights to co-develop and co-market Almorexant (the orexin receptor antagonist brought by the latter biotechnology company to the Phase III clinical stage for primary insomnia). The deal, also ranked as the largest development and commercialization transaction in the history of the bio-pharmaceutical industry, was structured to allow GlaxoSmithKline (licensee) to commit to the disbursement of $40 \%$ of development costs within the R\&D program led by Actelion. ${ }^{4}$

In the light of the above industry trends, our study seeks to provide a solution to the following challenges related to licensing deal-making: How do licensor and licensee decide how to structure a certain agreement? At which payment terms? With what roles and responsibilities?

Negotiations are often based upon the profit split ratio or PSR (the ratio of NPV of the R\&D program accruing to the licensee to that of the licensor) so the contract's remuneration reflects the PSR's NPV proportions. A licensing deal based on a standard remuneration structure (combining upfront fee/milestone payments with royalties) requires determining and apportioning those cash payments to licensor and licensee according to the PSR. The profit split ratio is commonly computed on the basis of the (passive or static) net present value (NPV) of the R\&D program. The biotechnology company would license-out the commercial use of one of the compounds (and the associated development projects) in its own R\&D pipeline to a pharmaceutical firm by foregoing the entire project value (- NPV) if this happens in exchange for obtaining a fair amount of fixed and use-based cash payments. Symmetrically, the pharmaceutical company would be happy to engage in the transaction, if the project value to be received $(+V)$ more than compensates for the contract-related and commercialization expenditures. Figure 1 provides a straightforward scheme of all cash flows underlying a standard, licensing agreement (as described above) and showing the interconnections existing among all the payments. If the profit split ratio (PSR) is defined as:

$$
P S R=\frac{V_{L E}}{V_{L R}}
$$

where:

4 Such a licensing-based transaction was beneficial to both GlaxoSmithKline and Actelion, with the former adding a first-class compound to its pipeline of insomnia drugs and the latter gaining access to the development expertise and primary-care commercialization platform of its partner while reducing the reliance (in terms of revenues) on its key blockbuster drug for pulmonary arterial hypertension (Tracleer). The economic terms of the deal consisted of an upfront fee of $\$ 139$ million, potential milestone payments of up to $\$ 384$ million and royalty-based payments of up to $\$ 3.058$ billion. 
$V_{L E}=$ value to the licensee (LE);

$V_{L R}=$ value to the licensor (LR)

and a standard NPV analysis is used, the passive net present value of the $\mathrm{R} \& \mathrm{D}$ program is given by the value (upon completion) of cash inflows expected from drug sales $(V)$ net of development [PV(D)] and commercialization costs [PV (C)]. Such a passive NPV that would accrue to the biotechnology company as R\&D owner is split between licensor and licensee as a result of the licensing agreement. The dotted arrows in Figure 1 correspond to the following conditional NPV equation:

$$
\text { conditional } N P V=V-[P V(D)+P V(C)]=V_{L R}+V_{L E}
$$

Fig. 1: Licensing-Related Cash Flows

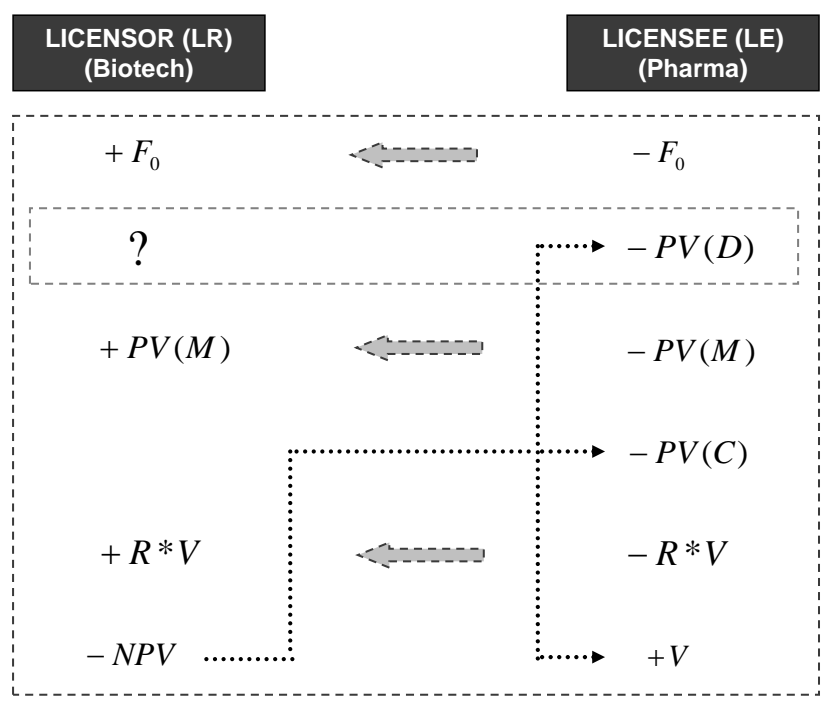

Up-Front Fee

Development Costs

Milestone Payments

Commercialization Costs

Royalties

Project Value

(Foregone/Received)

Source: Authors' Elaborations

Proper valuation of the IP asset (e.g., a patentable compound that, after further development, may become a marketable drug) and its associated PSR is crucial. However, appraising licensing agreements underlying multi-stage R\&D programs, such as those conducted in the bio-pharmaceutical industry, poses special challenges because of multiple sources of (market and technical) uncertainty that may interact. Standard NPV tools that focus on immediate payoffs and ignore key features of the underlying R\&D activity (exclusivity, irreversibility, uncertainty, staging) are unable to effectively assess the full value potential of these IP rights. For instance, 
under uncertainty the PSR does not properly reflect the value of the physical or contractual options embedded in the R\&D program or the licensing deal.

The aim of our study is to present a comprehensive real options approach to: (a) appraise the IP asset capturing the value of optionality embedded in the underlying drug R\&D program; (b) consider licensor and licensee perspectives in negotiating the terms of the IP licensing agreement providing guidelines on how to determine its optimal remuneration structure reflecting a fair sharing of project value and embedded optionality among the parties; (c) offer a tool for IP portfolio management that helps a licensor prioritize internal $R \& D$ projects accounting for managerial flexibility and optimal licensing design under uncertainty.

\section{IP licensing and management context: the cerep case study}

We analyze practical $R \& D$ valuation and licensing structuring problems in a managerial context using Cerep, a French biotech firm serving the pharmaceutical industry as a strategic partner in drug discovery like our illustrative case study. Founded in 1989 with a venture capital backing of \$500,000, Cerep grew to become a leader in pharmacological profiling services. It operates in two main business areas: services (75\% of its revenues) and research $(25 \%)$. In services, Cerep developed an integrated, innovative technology platform (Bioprint) for the implementation of new drug discovery thus reducing the time and cost involved in drug development for its customers (such as Bristol-Myers Squibb, Roche, Pfizer, Eli Lilly) via identification of the most promising drug candidates at an early stage and efficient elimination of molecules which would not survive the development phase.

As part of its own IP portfolio (research business), in 2005 Cerep gained access to an oncology program by acquiring the French biotech company Molecular Engine Laboratories (MEL) for $€ 4$ million. Cerep was interested in MEL's innovative approach to cancer treatment in tumor reversion, having identified a metabolite of the TCTP molecule presenting a more interesting toxicological profile. Its strategy was to recover MEL's project in Phase II by applying the newly discovered molecule to five different cancer indications for patients resisting other treatments and finding a pharmaceutical company as a licensing partner (with drug launch expected seven years from Phase II). Cerep's case is interesting due to its later involvement in proprietary research that enabled management to design a licensing strategy and review its IP portfolio.

To illustrate (a), we perform a real options valuation of Cerep's MEL oncology R\&D program and compare it to conventional NPV analysis.

The terms of the transaction arranged by Cerep to license-out the MEL-related molecule to a pharmaceutical partner are summarized as follows (see Panel A, Box). Cerep agrees to conduct the development of the candidate drug by going through all the remaining stages of the $\mathrm{R} \& \mathrm{D}$ program. The present value $(V)$ of the gross cash inflows expected from drug commercialization and conditional on the successful 
completion of the underlying R\&D program is $€ 222$ million $^{5}$. Phase II and Phase III will take 3 years to be completed respectively and FDA approval may be granted in only 1 year from date of filing. Probabilities of successful completion of each of these three stages are $60 \%, 57 \%$ and $90 \%$ respectively (reported at the beginning of the relevant phase in Panel A, Box). An upfront fee of $€ 10$ million is due to the licensor (Cerep) upon signature of the contract. Milestone payments are made by the licensee (pharmaceutical company) to Cerep upon successful completion of phase II ( $€ 5$ million), Phase III ( $€ 10$ million) and FDA approval ( $€ 25$ million) respectively. A total amount of $€ 27$ million is incurred by the licensee to allow Cerep to develop the molecule. Allocation of such development expenditures to the various stages of the R\&D program is the following: $€ 6$ million (Phase II); $€ 18$ million (Phase III); $€$ 3 million (FDA filing). The pharmaceutical company will also undertake the market commercialization of the candidate drug, if all $R \& D$ stages are successfully completed. The present value of launch and distribution costs that the pharmaceutical company will incur over time amounts to $€ 30$ million. The rate on the basis of which (after drug market launch) royalty payments are made by the licensee to Cerep is $5 \%$ (of $V$ ).

If Cerep and its pharmaceutical partner were to apply a standard (static or passive) NPV analysis of the licensing situation to determine the PSR based on which the remuneration structure of the deal (as presented above) would be negotiated, they could elect conditional or probability-adjusted NPV. The conditional NPV [based on equation (2)] is equal to $€ 173,8$ million. The probability-adjusted NPV is more sophisticated as it results from multiplying the net cash flows accruable to the R\&D owner by the (single or cumulative) probability associated with the successful completion of all subsequent stages. The probabilityadjusted NPV is $€ 42,4$ million and is apportioned between licensor ( $€ 24,8$ million) and licensee ( $€ 17,6$ million) based on a PSR of 0.7.

Conventional licensing valuation models are static in that they assess licensor and licensee's decisions as to whether to enter the agreement or not by only considering its immediate payoff effects based on a static revenue and cost-driven scenario and ignoring the stochastic, contingent nature of the underlying $R \& D$ process. A real options analysis of licensing deals instead encompasses the key features of the underlying R\&D program:

- exclusivity - the patent legally protecting the starting compound gives the R\&D process owner the exclusive right to commercialize the resulting drug;

- irreversibility - the cost of (pre)clinical trials cannot be recovered if the program is abandoned due to its negative results on patients. Thus, any R\&D program is irreversible (and development expenditures are sunk costs) unless the owner launches the drug into the market;

- flexibility - there is no obligation to continue investing in drug development if any

$5 € 222$ million results from adjustment for the market erosion factor $(\delta)$ according to the following formula: $V_{0}=V e^{\sqrt{-\delta t}}=250 e^{\sqrt{-1.7 \% * 7}}=222$ million. 
unfavorable circumstance occurs (e.g., a competitor preempts the market via an earlier patenting of the same molecule). In this sense, $R \& D$ investment decisions are of contingent (or optional) nature: only if market or technological conditions develop favorably, management will commit to make the follow-on investment, otherwise, the program will be halted altogether. This reveals the flexible nature of any $\mathrm{R} \& \mathrm{D}$ project;

- uncertainty - the technicality of a drug (during its development) and its market potential (after the development has been successfully completed) are uncertain;

- staging - drug development investments can be made in stages as technical uncertainty resolves itself.

Our proposed licensing appraisal model is based on the fact that any drug discovery and development program may be viewed as a real, staged (or compound) option (Trigeorgis, 1996) ${ }^{6}$. Drug development is typically carried out in optional stages, with technical uncertainty being gradually resolved ${ }^{7}$. Financing is also staged as a series of contingent "installments" with the earliest payment giving the right to make further investments in (pre)clinical trials, filing for drug approval or proceeding with market launch - a compound option. At each stage, the R\&D owner (licensor or licensee) pays an investment cost $(I)$ to acquire the option to proceed to the subsequent stage. Each phase is characterized by a probability of technical success $(\mathrm{P})$. The program is halted if any of the staged options to proceed is not exercised. Drug commercialization is achieved if all intermediate options are exercised.

The $\mathrm{R} \& \mathrm{D}$ process for discovering, testing and marketing a new drug can thus be modeled as a compound (growth) option as the value of the R\&D program depends upon the future growth opportunities that all earlier contingent investments may open up via the subsequent drug commercialization. The underlying asset value (gross $V$ ) of all staged options is the present value of the real claim the owner has on the net cash flows expected from drug commercialization (with maturities corresponding to the actual time of each $\mathrm{R} \& \mathrm{D}$ stage).

We suggest that parties may engage in licensing deal-making actively or passively. If both parties ignore the option-like features of the underlying $\mathrm{R} \& \mathrm{D}$ program, they will engage in the transaction passively, thus sharing the purely static (conditional or probability-adjusted) NPV of the licensed molecule (as above

6 Real options analysis has been extensively used to value R\&D projects (Pindyck, 1993; Childs and Triantis, 1999; Pertlitz et al., 1999; Herath and Park, 1999; Schwartz and Moon, 2000; Paxson, 2001; Smit and Trigeorgis, 2004; Miltersen and Schwartz, 2004; Berk et al., 2004; Lewis et al., 2004) and patents (Schwartz, 2004).

7 A drug development program is typically divided into 7 stages (subdivided into 3 macrophases): Phase 1 - Discovery (preliminary studies on specific molecules with potential to become new drugs); Phase 2 - Testing (4 stages: Pre-Clinical, Phases I, II, and III); Phase 3 - Market (drug approval from the competent national authority and subsequent commercialization). Stage investment requires less capital absorption compared to immediate investing. 
described). Active management of the IP licensing deal implies maintaining control over the exercise of the compound (real) option embedded in drug discovery by commanding the disbursement of the development costs. Three types of licensing agreements are examined depending on which party commands such embedded optionality: I) the licensee (LE) pays the development costs and controls the R\&D continuation (or abandonment) option; II) the licensor (LR) pays development costs and takes control over the compound option with such costs being reimbursed by the licensee; III) the licensor pays the development costs (with no reimbursement but compensation based on a higher royalty rate) and controls the compound option. IP asset values accruing to licensor and licensee, in each of the three contract schemes are determined based on the notion of expanded (or strategic) NPV (E-NPV) of the underlying R\&D program. We formulate predictions on how the $E-\mathrm{NPV}$ of the R\&D program underlying the licensing agreement would be split between the parties under three licensing schemes (one symmetric and two asymmetric favoring the licensor at the expense of the licensee or vice versa depending on who pays and controls the interim drug development expenditures) (Table 1).

Tab. 1: Licensing Contract Schemes: E-NPV and Associated PSR Results

\begin{tabular}{|l|c|c|c|c|c|}
\cline { 5 - 6 } \multicolumn{2}{l|}{} & $\begin{array}{c}\text { LICENSOR (LR) } \\
\text { (Biotech) } \\
\text { E-NPV }\end{array}$ & $\begin{array}{c}\text { LICENSEE (LE) } \\
\text { (Pharma) } \\
\text { E-NPV }\end{array}$ & E-NPV & $\begin{array}{c}\text { E-NPV-Based } \\
\text { PSR }\end{array}$ \\
\hline I) Licensee pays Development Costs (D) & LENTROL & $€ 24,80$ & $€ 24,48$ & $€ 49,28$ & 1,0 \\
\hline $\begin{array}{l}\text { II) Licensor pays Development Costs (D) } \\
\text { and gets reimbursed }\end{array}$ & LR & $€ 24,24$ & $€ 18,17$ & $€ 42,41$ & 0,7 \\
\hline $\begin{array}{l}\text { III) Licensor pays Development Costs (D) } \\
\text { with no reimbursement(but higher royalty } \\
\text { rate) }\end{array}$ & LR & $€ 17,91$ & $€ 24,49$ & $€ 42,40$ & 1,4 \\
\hline
\end{tabular}

Source: Authors' Elaborations

Under licensing contract scheme I, the licensee (pharmaceutical company) actively controls drug development even if the actual R\&D work is attributed to the licensor (biotechnology firm). Following the cash flow interconnections and allocations underlying a standard licensing agreement summarized in Figure 1, the real options-based $E$-NPV $\left(V^{\prime}\right)$ of such a licensing contractual arrangement is apportioned to licensor and licensee as follows:

$V_{L R}^{\prime}=\left[F_{0}+P V(M)+R V^{\prime}\right]$

$V_{L E}^{\prime}=-\left[F_{0}+P V(D)+P V(M)+P V(C)\right]+V^{\prime}(1-R)=$

$=\left\lfloor V^{\prime}-P V(D)-P V(C)\right\rfloor-\left\lfloor F_{0}+P V(M)+R V^{\prime}\right\rfloor=V^{\prime}-V_{L R}^{\prime}$ 
Under such a contract scheme, the portion of the licensing contract's expanded NPV accruable to the licensor $\left(V_{L R}^{\prime}\right)$ corresponds to the present value of cash inflows committed by the licensee in the form of contractual remuneration payments (upfront fee, milestones, royalties) and may be thus traditionally determined using a standard, static NPV analysis [(equation 3)]. Indeed, no optionality is involved on the part of the licensor under this circumstance ${ }^{8}$. As shown by equation (4), the licensee instead receives $V_{L E}^{\prime}$, which corresponds to the expanded NPV ( $E$-NPV or $V^{\prime}$ ) of the licensing contract value net of the value component of the transaction accruing to the licensor.

To appraise the value of the licensing contract to the licensee $\left(V_{L E}^{\prime}\right)$ and embedded R\&D-related options, we build up a real options analysis following a discrete-time numerical approximation procedure (as described below). Drug development can be seen as a contingent plan of interrelated investment decisions. There are five key phases to structure the problem from a strategic perspective and implement the related valuation process. To estimate the value of the R\&D program taking into account the managerial flexibility represented by the portfolio of embedded real options, it is necessary to determine: (1) the (residual) stages of the candidate drug development; (2) embedded real options (often accounting for their mix in a layered or sequential structure); (3) connections and interdependence among the options; (4) key value drivers (i.e., the sources of uncertainty on which option values depend); (5) financial parameters (e.g., risk-free rate).

Inputs for Multi-Stage Option Valuation and Excel-Based Appraisal

Consider the case of licensing contract I where the licensee (pharmaceutical company) incurs development costs so as to control the optionality embedded in the underlying R\&D program (exercise of compound option) and the licensor passively receives the payment flow (upfront fee, milestones, royalties).

Uncertainty is modeled by a binomial lattice approach where the value of the R\&D program $\left(V_{0}\right)$ can either move up $\left(u=e^{\sigma \sqrt{t}}=1.8\right)$ or down $(d=1 / u=0.5)$ depending on the candidate drug market demand. Related volatility $(\sigma)$ is $60 \%$. The resulting binomial tree below represents the future evolution of the candidate drug value across subsequent $R \& D$ stages until its (possible) successful launch in the market (Panel B).

The licensing contract value $\left(V^{\prime}\right)$ based on the expanded NPV criterion is derived by dividing the compound valuation process into 4 steps corresponding to

8 Whoever (licensor or licensee) is not in command of (or possibly ignores) the optionality embedded in the underlying R\&D program undertakes her relevant, stage-related tasks in a passive fashion. It follows that NPV is the most appropriate criterion for appraising the value of the licensing deal accruable to the passive party. 
the 4 residual stages (clinical Phase II and III, FDA approval, commercialization) the molecule must go through to become a marketable drug. Each step must account for the probability with which the licensee will successfully complete the relevant (clinical, approval or market launch) stage by bringing the candidate drug forward in the $\mathrm{R} \& \mathrm{D}$ process ( $\mathrm{P}$, probability of technical success). Compound option valuation is performed by working backward the molecule values in the binomial tree across the various up and down states. At each relevant stage (clinical Phase II and III, FDA approval, commercialization), the payoff structure of the option exercisable by the licensee is the same:

$$
V_{t}^{\prime}=\max [\mathrm{P} * V-I]
$$

At the launch/commercialization stage $(\mathrm{t}=7)$, the associated option payoff is $V_{t}^{\prime}=\max \left[\mathrm{P}_{\mathrm{L}} * V_{7}(1-R)-I_{L}\right]$, where $\mathrm{P}_{L}(=1)$ is the probability of commercializing the drug after FDA approval, $V_{7}$ is the value of the molecule at year 7 (contingent on the up/down state), $R$ is the royalty rate and $I_{L}(=€ 55$ million) is the investment cost that needs to be incurred to launch the drug into the marketplace. It follows that upon successful completion of the FDA approval the licensee is granted the option to commercialize the drug (with probability 1) by appropriating the present value of associated future cash inflows from sales net of royalty payments (due to the licensor) and marketing costs. By proceeding backward along the binomial tree, the preceding molecule values are calculated in the form of continuation value (discounted expected payoff) or $C_{t}=\left[p V_{t+1}^{u}+(1-p) V_{t+1}^{d}\right] e^{-r d t}$ where: $V_{t+1}^{u}$ and $V_{t+1}^{d}$ are the future option payoffs (under the up and down demand states) at the subsequent node at time $t+1 ; p(=0.4)$ and $1-p(=0.6)$ are the risk-neutral probabilities; $e^{-r d t}(=0.97)$ is the discount factor in continuous time (with risk-free rate or $r=3,5 \%$ ). For instance, if the licensee were only to appraise the licensed molecule at time 0 contingent on the successful completion of launch stage, its value would be $€ 172,13$ million.

The same backward induction procedure is applied to precedent stages. At FDA approval stage $(\mathrm{t}=6)$, the associated option payoff is $V_{t}^{\prime}=\max \left[\mathrm{P}_{\mathrm{FDA}} * C_{6}-I_{F D A}\right]$ and the licensed molecule value at time 0 contingent on the successful completion of this stage is $€ 147,45$ million. At Phase III stage $(t=3)$, the associated option payoff is $V_{t}^{\prime}=\max \left[\mathrm{P}_{\mathrm{III}} * C_{3}-I_{I I I}\right]$ and the licensed molecule value at time 0 contingent on successful completion of such stage is $€ 67,46$ million. At Phase II stage $(\mathrm{t}=0)$, the associated option payoff is $V_{t}^{\prime}=\max \left[\mathrm{P}_{\mathrm{II}} * C_{0}-I_{I I}\right]$ and the licensed molecule value at time 0 contingent on the successful completion of this stage is $€ 24,48$ million. The Phase II-value of the licensed molecule at time 0 represents the deal value accruing to the active licensee if contract scheme I is chosen by the parties. 


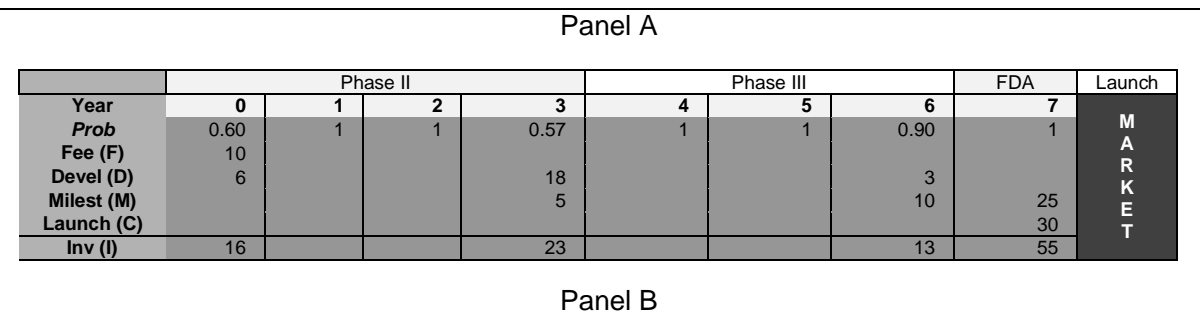

Evolution of Underlying Asset Value (Binomial Tree)

\begin{tabular}{|c|c|c|c|c|c|c|c|c|}
\hline 0 & 250.00 & 455.53 & 830.03 & 1512.41 & 2755.79 & 5021.38 & 9149.56 & 16671.58 \\
\hline 1 & & 137.20 & 250.00 & 455.53 & 830.03 & 1512.41 & 2755.79 & 5021.38 \\
\hline 2 & & & 75.30 & 137.20 & 250.00 & 455.53 & 830.03 & 1512.41 \\
\hline 3 & & & & 41.32 & 75.30 & 137.20 & 250.00 & 455.53 \\
\hline & & & & & 22.68 & 41.32 & 75.30 & 137.20 \\
\hline 5 & & & & & & 12.45 & 22.68 & 41.32 \\
\hline & & & & & & & 6.83 & 12.45 \\
\hline & & & & & & & & 3.75 \\
\hline
\end{tabular}

Launch/Commercialization $(\mathrm{t}=7)$

$\max \left(\mathrm{PL} L^{*} \mathrm{~V} 7(1-\mathrm{R})-\mathrm{IL}, 0\right)$

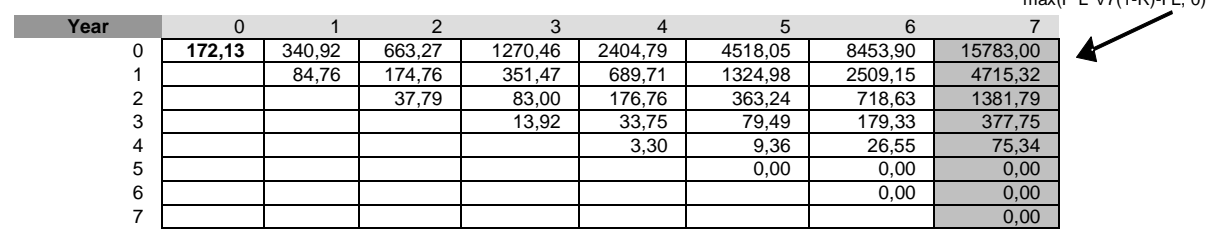

FDA Stage $(t=6)$

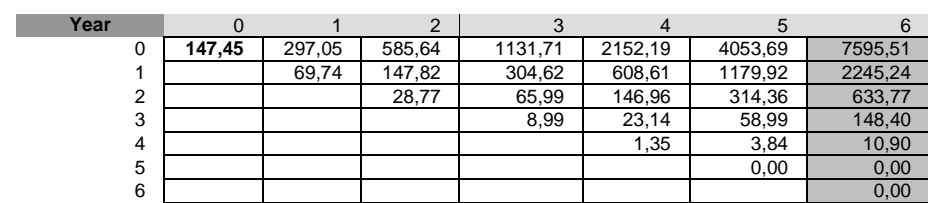

$\max \left(\mathrm{PFDA}{ }^{*} \mathrm{C6}-\mathrm{I}\right.$ FDA, 0

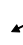

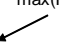

Phase III $(\mathrm{t}=3)$

$\begin{array}{rrrrrr}\text { Year } & 0 & 1 & 2 & 3 & \max \left(\mathrm{P}_{\mathrm{III}}^{*} \mathrm{C}_{3}-\mathrm{III}, 0\right)\end{array}$

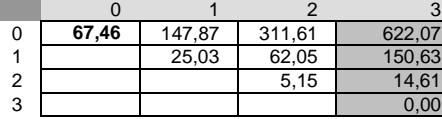

Phase II $(\mathrm{t}=0)$

\begin{tabular}{c|c} 
Year & 0 \\
\cline { 3 - 3 } & $\max \left(\mathrm{P}_{\|}{ }^{*} \mathrm{C}_{0} \|, 0\right)$
\end{tabular}

Source: Authors' Elaborations

A strategic licensing investment can then be structured and graphically represented by means of an option map, which describes the essential structure of the underlying $R \& D$ project from a strategic perspective and establishes the timing, staging, and interrelationships among the embedded options. It can be represented as a collection of nodes and branches. Each node on the map indicates an option (a 
hexagon), or a decision operator (a box), which links several options (or a known cash flow). Any option is characterised by the payoff and its timing (maturity). In the case of an R\&D project with value of expected cash flows $V$ and cost $I$ (both possibly affected by uncertainty), the payoff (which depends on the value of the state variables) is given by $V-I$. The hexagon implies a discretionary decision, so the option node actually takes the maximum between the NPV or $V-I$ (if the licensee invests) and zero (if she does not invest). In the case of licensing contingent on drug development, the average (AVG) decision operator permits to average different courses of action (proceed to the next R\&D phase or abandon) in the presence of technical uncertainty, accounting for a specified discrete probability of success or failure.

Complex map configurations can be obtained by suitably combining options with appropriate decision operators and branches. A link or branch is a connection between any two of the above decision elements (options, decision operators). Drug development adds more complexity as it can be viewed as a multi-stage compound option, where options interact among each other being economically and chronologically interconnected. In Figure 2A, the Phase II and Phase III options are linked by a branch with the option on the left (Phase II) being a "cause" for the option on the right (Phase III) ${ }^{9}$. In such a setting, the underlying asset of the earlier option (Phase II) includes the value of the follow-on option (Phase III). The value of the licensing contract scheme $\mathrm{I}$ is calculated as a compound option working backward in time through the various stages of the binomial tree shown in Figure 2A. The applied principle is that of dynamic programming implemented within riskneutral valuation, where the whole sequence of decisions is broken down into two main components: the immediate decision with its payoff consequences, and a continuing valuation function that incorporates the consequences of all subsequent optimal decisions (starting from the position that emanates from the immediate decision).

In Figure 2A, Cerep's pharmaceutical partner (which incurs development costs and thus controls the embedded optionality) may have a $60 \%$ probability of successfully completing the current Phase II and taking the candidate drug to the next stage (Phase III). To exercise the option to complete Phase II, the licensee must incur development costs of $€ 6$ million and pay an upfront fee of $€ 10$ million to the licensor for remunerating its internal $\mathrm{R} \& \mathrm{D}$ efforts. If (with the residual $40 \%$ probability) technical uncertainty does not resolve itself over the 3-years duration of Phase II and the licensor's R\&D process does not prove to be successful, the licensee will exercise the option to abandon (or halt) the R\&D program altogether. Exercise of the first-stage option opens up for the licensee a follow-on possibility (at $t=3$ ) to proceed to the next development phase (Phase III). Similarly, the licensee

9 Branches may link other items rather than options such as decision operators or cash flows. What takes place on the right may happen only after (because of) the item on the left has taken place. Moreover, the value of the element on the left is dependent on the value of the element on the right (in a backward recursion sense). 
will optimally exercise the option to complete Phase III if the current value of the licensed molecule is higher than the sum of development costs ( $€ 18$ million) and milestone payment ( $€ 5$ million) due to the licensor as a compensation of the related R\&D efforts. The probability of successfully completing Phase III is 57\%. As the R\&D project progresses successfully (e.g., filing to the Federal Drug Authority and obtainment of related drug approval with $90 \%$ success chance; after FDA approval, drug commercialization with $100 \%$ probability), the value of the licensed molecule to the licensee increases (up to $€ 172.1$ million upon market launch).

The optimal licensing strategy (under contract scheme I) for the licensee is derived by working backward the underlying molecule values in the binomial tree of Figure $2 \mathrm{~A}$ across the various $\mathrm{R} \& \mathrm{D}$ stages within a compound option valuation framework. The value of the licensing contract to the active licensee (contingent on successful completion of all subsequent R\&D stages) corresponds to the Phase IIvalue of the licensed molecule at time 0 ( $€ 24,48$ million).

Figure 2B shows how to derive the value of the licensing contract to Cerep (passive licensor/biotech company) when (under contract scheme I) it is in charge of conducting drug development without incurring related costs, thus being unable to control the embedded optionality. In exchange for its $R \& D$ efforts, the licensor receives the present value of the stream of fixed and royalty payments made by the active licensee. Each node on the map is no longer represented by a hexagon (option or discretionary decision) but is substituted by a rectangular box (committed decision), which denotes a known cash flow (upfront fee, milestone payment, royalty payment) accruing to the licensor across time. Several rectangular boxes are linked together by branches. The value of the licensing contract to the passive licensor (contingent on successful completion of all subsequent R\&D stages) corresponds to the present value of fixed and use-payments at the beginning of Phase II or time 0 ( $€ 24,80$ million). Licensor and licensee equally share a licensing value pie of $€ 49,28$ million with an $E$-NPV based-PSR of 1.0.

Fig. 2: Valuing an IP Licensing Deal as a Multi-stage Option (Cerep's MEL Oncology $R \& D$ Program). Scenario I: Licensee (LE) pays development costs and controls optionality

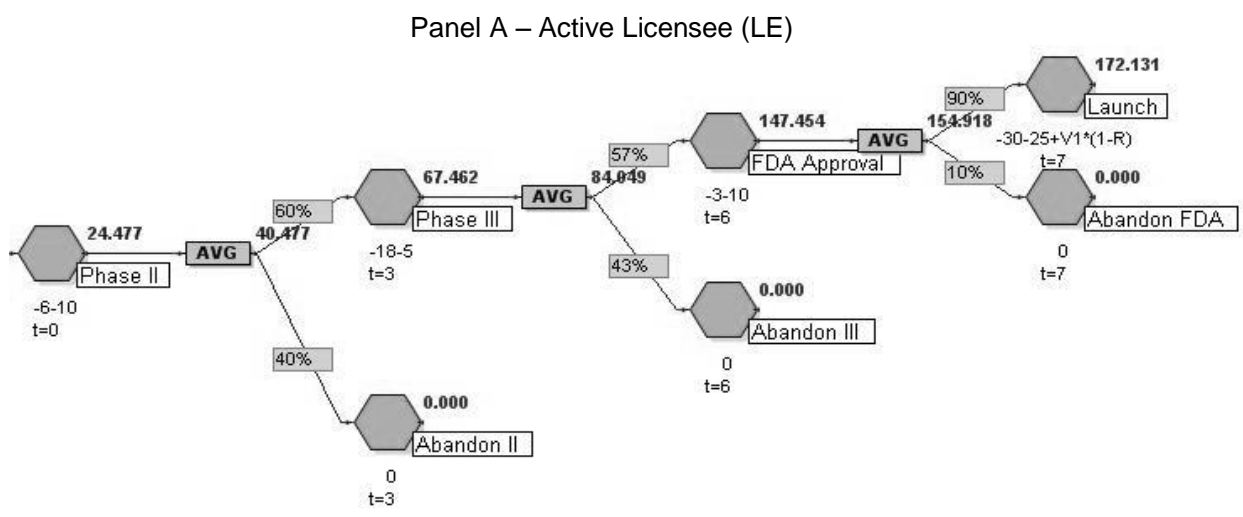


Panel B - Passive Licensor (LR)

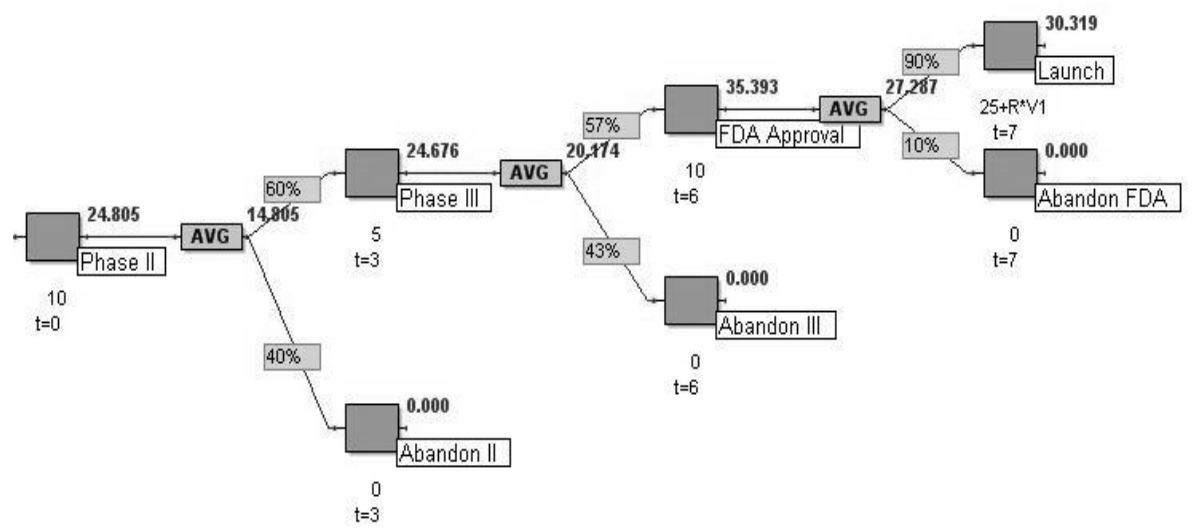

Source: Authors' Elaborations

Under licensing contract scheme II, the licensor actively undertakes the candidate drug development by managing the underlying $\mathrm{R} \& \mathrm{D}$ program and incurring the related expenditures. However, there is no financial burden for the licensor acting as R\&D owner as it benefits from the full reimbursement of development costs directly made by the licensee in exchange for its internal R\&D efforts. In the option map of Figure 3 hexagons reflect the optionality that the licensor may exercise by controlling the various R\&D stages underlying the licensing contract via disbursement of related development expenditures. Boxes account for cash inflows in the form of both the licensee's reimbursements of development costs accruing to the licensor one year after the latter's actual disbursement and the licensee's contractual remuneration payments (upfront fee, milestones, royalties). The licensee, in turn, only commits to conducting a drug market launch and related distribution activities once the R\&D program underlying the licensing agreement has been completed by the licensor. For the latter to accomplish such a goal, the licensee passively incurs development costs and contractual remuneration payments. The licensee's remuneration consists of the present value of future cash flows from drug sales net of development expenditure reimbursements as well as on-going fixed (upfront fee and milestones) and usebased (royalties) payments. Licensor and licensee share a licensing value pie of $€$ 42,41 million with an E-NPV based-PSR of 0.7. The active licensor appropriates $€$ 24,24 million, while the residual $€ 18,17$ million accrue to the passive licensee. 
Fig. 3: Valuing an IP Licensing Deal as a Multi-stage Option (Cerep's MEL Oncology $R \& D$ Program). Scenario II: Licensor (LR) pays development costs (but gets reimbursed) and controls optionality

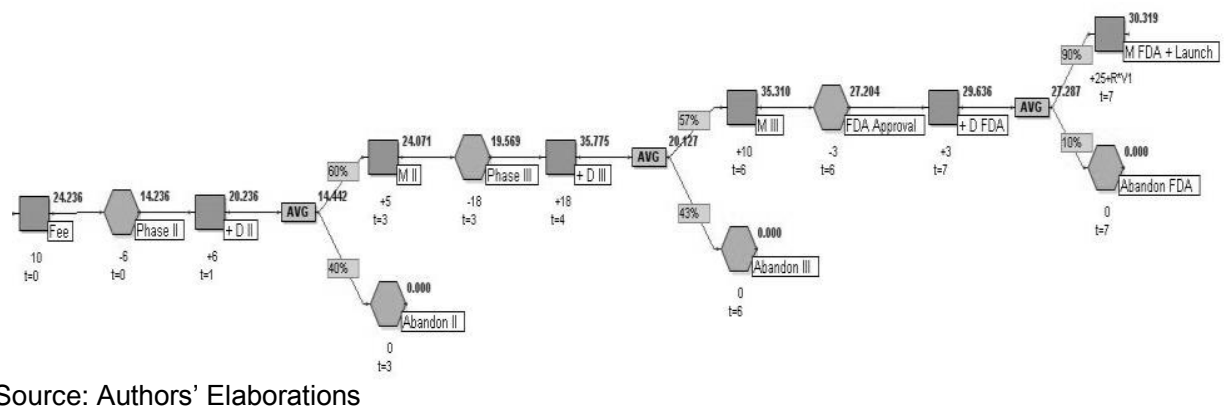

Under licensing contract scheme III, the biopharmaceutical company (licensor) is still engaged in actively managing the $R \& D$ program based on the recognition of its option-like features but drug development expenditures are not reimbursed by the licensee. The absence of any reimbursement clause in the licensing contract may create a market disincentive and requires some form of compensation. To ease her own financial burden and re-allocate it proportionally among the parties, the licensor can therefore only commit to subsidizing drug development in exchange for receiving more contractual payments in the form of upfront/milestones or royalties from the licensee. For example, the licensor may accept to undertake drug development with no reimbursement of related $\mathrm{R} \& \mathrm{D}$ expenditures by appropriating a higher flow of royalty payment (based on an increase in the royalty rate) when the R\&D program has been completed and the drug is being launched in the marketplace. Similarly to the previous case, hexagons are the discretionary control decisions or options embedded in the R\&D program that the licensor may optimally exercise by paying related costs and boxes account for cash inflows in the form of the licensee's contractual remuneration payments (upfront fee, milestones, royalties) (Figure 4B). The licensee would in turn be willing to increase the royalty rate (from $5 \%$ to $19.6 \%$ ) and pay out more royalties to the licensor as long as she is indifferent (in terms of the portion of the licensing, E-NPV-based value pie appropriated) between developing the candidate drug herself by incurring related expenditures and allowing the licensor to develop it without reimbursement in exchange for the payment of additional royalties (Figure 4A). It follows that the appraisal of the $E$ NPV-based PSR under licensing contract scheme III is based on the determination of the break-even royalty rate that renders the licensee passively indifferent between direct drug development and give-up of more future revenues (in the form of additional royalty payments) to the benefit of the active licensor. Break-even royalty rate is $19.6 \%$ so as to allow licensor and licensee to share a licensing value pie of $€$ 42,40 million with an $E$-NPV based-PSR of 1.4 , the active licensor receiving $€$ 
17,91 million, and the licensee still appropriating $€ 24,49$ million (as if the parties were to follow the licensing contract scheme I) ${ }^{10}$.

Fig. 4: Valuing an IP Licensing Deal as a Multi-stage Option (Cerep's MEL Oncology $R \& D$ Program). Scenario III: Licensor (LR) pays development costs (without reimbursement) and controls optionality

Panel A - Passive Licensee (LE)

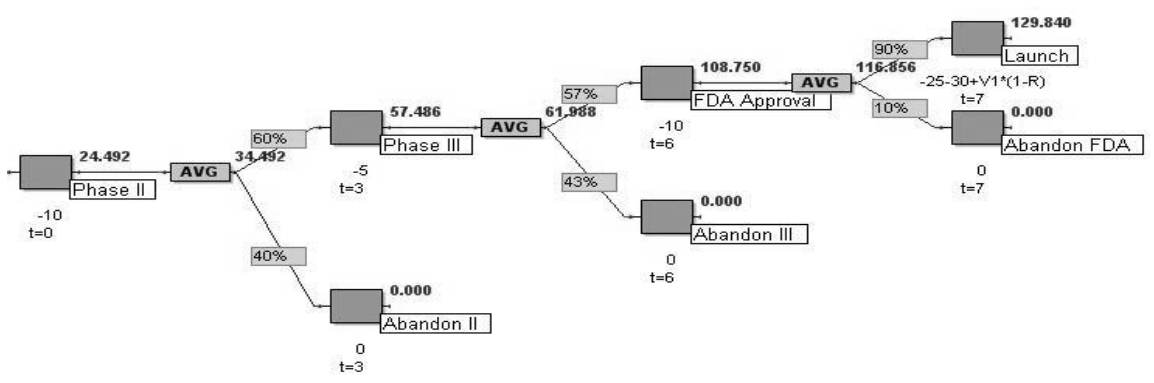

Panel B - Active Licensor (LR)

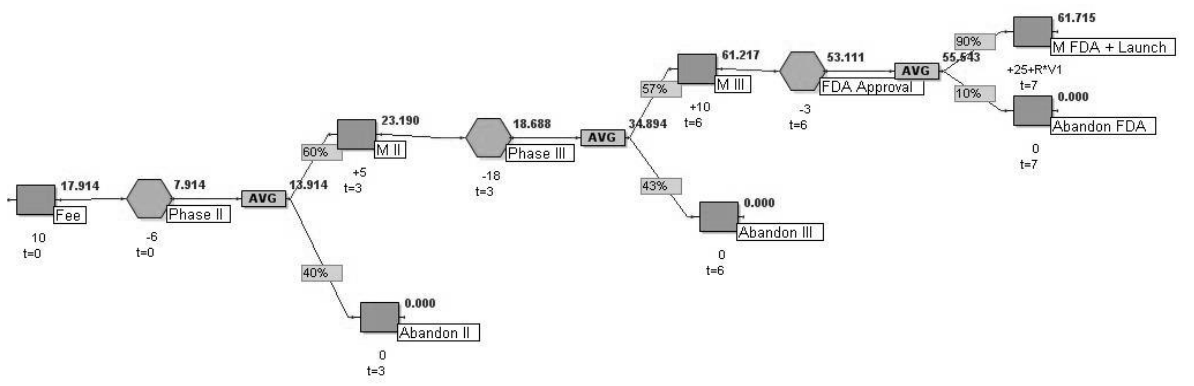

Source: Authors' Elaborations

Based on the above analysis, we can formulate our predictions on how the expanded NPV of the R\&D project underlying the licensing agreement would be split between the parties under the three licensing scenarios. If the first type of licensing contract is chosen (scheme I), the value of the underlying R\&D program would almost equally accrue to both licensor and licensee so as to reflect the symmetric nature of the agreement. If the second type of licensing contract is selected (scheme II), the partition of the R\&D project value would be favorably apportioned to the licensor (at the

10 If the royalty rate were to remain at $5 \%$, the licensing value pie would be $€ 44,15$ million with an unbalanced sharing between parties as the licensee would appropriate $€ 34,15$ million and the licensor only $€ 10$ million. The licensee would experience a higher licensing value appropriation at the expense of the licensor. 
expense of the licensee) because of the presence of the reimbursement clause that complements the fixed and use-based payments due to the licensor. Under application of the third licensing scheme (scheme III), the R\&D project value sharing would unduly favor the licensee due to the fact that the licensor fully incurs drug development expenditures. In this sense, the royalty rate upgrade may partially re-balance the terms of the deal allowing value extraction from the licensee to the benefit of the licensor.

As for (b) above, we aim to find the combination of fixed (up-front fee and milestones) and use-based (royalty) payments that is PSR-neutral to licensor and licensee but sets the best incentives for both parties engaging in profitable dealmaking. Knowing to what extent milestones and royalties are substitutable (with neutral impact on R\&D program value distribution among the parties) may help (1) improve or custom design the licensing contract selecting among a menu of isovalue choices, (2) ease and allow for customization of the licensing negotiation process, facilitating its further diffusion in the industry. Figure 5 shows that under licensing contract scheme I the licensor can negotiate the terms of the licensing contract so as to appropriate the same expanded NPV by differently combining the sum of fixed (upfront fee and milestones) and royalty payments that the licensee will agree to make. More specifically, the licensor may be able to receive the same amount of money ( $€ 24,80$ million) along an Iso $E$-NPV curve as a result of a remuneration structure that varies depending on the weight given to fixed versus use-based payments. For example, three different combinations of these two types of contractual payments [ $€ 58$ million and royalty rate: $2 \%(\mathrm{~A})$; fixed: $€ 50$ million and royalty rate: $5 \%(\mathrm{~B})$; fixed: $€ 39$ million and royalty rate: $10 \%(\mathrm{C})]$ would yield the same portion of $E$-NPV accruing to the licensor. As the royalty rate payable by the licensee as a percentage of future drug sales increases, the total amount of fixed payments that she is obliged to pay out to the licensor must be adjusted downward (and conversely, if the royalty rate decreases).

Fig. 5: Iso-Value Choices for Licensor (LR) (Contract Scheme I)

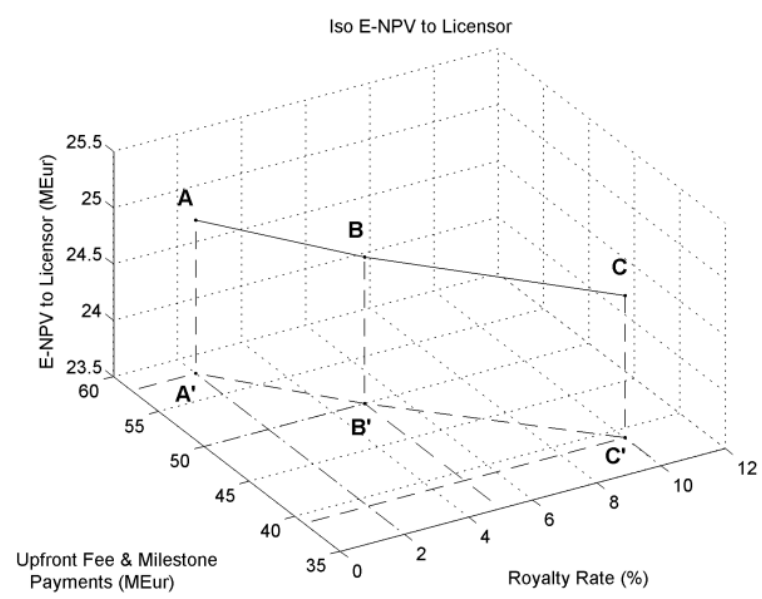

Source: Authors' Elaborations 


\section{Managerial implications}

There are several key implications of our study for IP managers. Using the Cerep case, we illustrate the use of real options methodology to: (1) value actual licensing opportunities (accounting for compound options and success probabilities); (2) examine how negotiation practices between IP licensor and licensee should be revised under uncertainty in light of real options theory; (3) provide practical guidance on how to optimize the set up of the licensing remuneration structure (e.g., tradeoff between who makes the R\&D installment payments and maintains control over the noncontinuation option); (4) present management of either party in the licensing negotiation with equivalent alternative choices and payment terms tradeoffs that are custom tailored to their specific preferences, as well as financial or other capabilities while being structured optimally and fairly. A main management take-away is that real options thinking leads to different perspectives and possibilities on how patent licensing agreements should be structured properly accounting for who controls the embedded optionality.

As for (c), we provide a means for quantifying the notion that any investment decision undertaken by an entrepreneurial company should consider both its immediate payoff and future growth potential. At any stage of development (from molecule into a marketable drug) the total value of the $R \& D$ program can be viewed as the sum of the present value of the cash inflows from expected drug sales net of development and commercialization costs (static NPV) plus the present value of growth opportunities embedded in the staged $R \& D$ process [compound (growth) option]. We propose a drug growth options (GO) matrix where existing (patented) and new (patentable) drug development opportunities are categorized into four different regions in option-value space based on their current "cash flow" (NPV) versus "growth option" (GO) potential (Figure 6). The horizontal axis measures the static NPV of R\&D projects (currently in place or realizable in the future) capturing present profitability from immediate, passive investing. The vertical axis measures the extra strategic value resulting from exploiting the same (existing or new) projects as a growth platform. Hence, it captures the value of the staged (or compound) development of drug-related growth opportunities evolving as technical and market uncertainty is resolved (Present Value of Growth Opportunities, PVGO).

In the GO matrix, drug development opportunities (and associated chemical compounds patented by the biotech firm) may fall in four different regions in option-value space based on their current "cash flow" (NPV) versus "growth option" (PVGO) potential. The bottom-right of the GO matrix (region IV) comprises compounds whose further development can be rapidly accomplished under low uncertainty and related new drugs brought to market with a prospective commercial success. It results that their strategic growth option potential is rather modest but their NPV is high. As these compounds are "cash cows", the suggested managerial action is to complete development and commercialize them. In the bottom-left region of the GO matrix (region III) there are compounds with both low current commercial and growth option potential that should be divested now. By 
recognizing early in the $R \& D$ process that these projects may be hampered by high technical uncertainty involving molecules that, if properly developed, may lead to poorly attractive drugs under current and future market conditions, abandonment (for salvage value, if any) is the most appropriate strategy.

The top-left region of the GO matrix (region I) accommodates compounds that are currently unprofitable but have high growth option potential. As the biotech company identifies one or some of its $\mathrm{R} \& \mathrm{D}$ projects as classifiable into this region of the option-value space, it should invest more resources into their full development in order to turn them into "licensable" drugs to pharmaceutical firms upon R\&D completion and authority approval. The strategic path to follow is then to move these projects from region I to region II. Region II is indeed the portion of the option-value space where all compounds comprised in the biotech firm's R\&D portfolio, for which staged development has been successfully terminated, may be licensed out in order to capture not only the immediate value of direct cash inflows but also the extra strategic value of their follow-on growth opportunities such as those connected to the "market for technology" (e.g., licensing) (Arora et al., 2001; Arora and Fosfuri, 2003). Drug development programs in regions III and IV are less risky as there is a low degree of technical and market uncertainty involved, while those falling in regions I and II are riskier due to the fact that potential upside opportunities can be exploited by committing to invest more at subsequent stages. Nevertheless, risk can be mitigated (or totally eliminated) by having the right (not the obligation) not to advance development if conditions turn out to be unfavorable (divestiture in region III is always possible)

The GO matrix provides guidance to a biotech company on how to strategically analyze the impact of its $R \& D$ portfolio composition on shareholder value, prioritize internal $R \& D$ budgets and flexibly manage its $R \& D$ pipeline based on real exploitation and exploration potential.

Fig. 6: GO Matrix for IP Portfolio Management

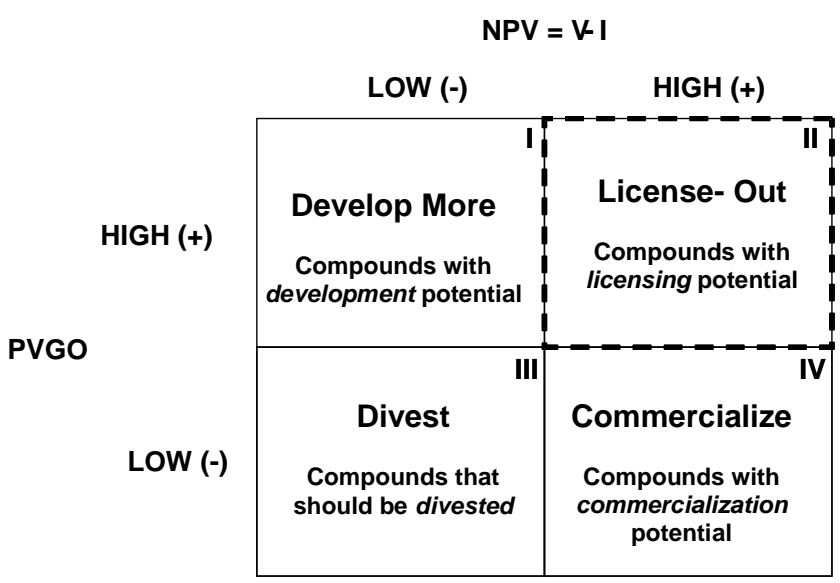

Source: Authors' Elaborations 


\section{Conclusions}

Our preliminary findings show that accurate valuation of all opportunities embodied in a licensing agreement is important for conducting an effective negotiation between the parties. Appraisal and negotiation are made even more difficult by the complexity of the remuneration structure used in the biopharmaceutical industry transactions. More specifically, IP management practices may tend to change depending on who pays for the development costs, controls the continuation/development or abandonment option and thereby appropriates most of the embedded option's value.

Our approach is extendable to the context of venture capital (VC), where complex agreements are commonly negotiated to allow the venture capitalist to condition its ongoing remuneration and investment exit upon the entrepreneurial firm's successful development and commercialization of an early-stage, prototypical product (or process) characterized by a highly risky technological content.

Despite intrinsic limitations (e.g., case-based, lack of empirical validation), our study offers two main contributions: (1) it complements strategic partnership literature on value creation and value capture with the real options logic; (2) it examines how perspectives and negotiation practices between IP licensor and licensee of IP change under uncertainty in light of real options theory with important implications for IP managers.

\section{References}

ANANDA BN., KHANNA T. (2000), "The structure of licensing contracts", The Journal of Industrial Economics, vol. 48, n. 1, pp. 103-135.

ARORA A., FOSFURI A., GAMBARDELLA A. (2001), "Markets for technology and their implications for corporate strategy", Industrial and Corporate Change, vol. 10, n. 2, pp. 419-451.

ARORA A., FOSFURI A. (2003), "Licensing the market for technology", Journal of Economic Behavior and Organization, vol. 52, n. 2, pp. 277-295.

ARORA A., CECCAGNOLI M. (2006), "Patent protection, complementary assets and firm's incentives for technology licensing", Management Science, vol. 52, n. 2, pp. 535-554.

BEGGS AW. (1992), "The licensing of patents under asymmetric information", International Journal of Industrial Organization, vol. 10, n. 2, pp. 171-194.

BERK JB., GREEN RC., NAIK V. (2004), "Valuation and return dynamics of new ventures", Review of Financial Studies, vol. 17, n. 1, pp. 1-35.

BESSY C., BROUSSEAU E., SAUSSIER S. (2004), "Payment schemes in technology licensing agreements: a transaction cost approach", Working Paper FORUM, Université Paris X \& ATOM.

BOUSQUET A., CREMER H., IVALDI M., WOLKOWICZ M. (1998), "Risk sharing in licensing", International Journal of Industrial Organization, vol. 16, n. 5, pp. 293308.

CAP GEMINI ERNST \& YOUNG. (2001), Perspective on Life Science, 3(Fall).

CAVES E., CROOKELL H., KILLING JP. (1983), "The imperfect market for technology licenses", Oxford Bulletin of Economics and Statistics, vol. 45, n. 3, pp. 249-267. 
CHESBROUGH H. (2003), "The logic of open innovation: managing intellectual property", California Management Review, vol. 45, n. 3, pp. 33-58.

CHILDS P., TRIANTIS AJ. (1999), "Dynamic R\&D investment policies", Management Science, vol. 45, n. 10, pp. 1359-1377.

CRAMA P., DE REYCK B., DEGRAEVE Z., CHONG W. (2007), "R\&D project valuation and licensing negotiations at Phytopharm plc", Interfaces, vol. 37, n. 5, pp. 472-487.

CRAMA P., DE REYCK B., DEGRAEVE Z. (2008), "Milestone payments or royalties? Contract design for R\&D licensing", Operations Research, vol. 56, n. 6, pp. 15391552.

DIMASI JA. (2001), "New drug development in U.S. 1963-1999”, Clinical Pharmacology Therapeutics, vol. 69, n. 5, pp. 286-296.

DRUG WEEK. (2003), Study shows pharmaceutical licensing deals stem from existing relationships. http://www.newsrx.com./newletters/Drug-Week/2003-12-26.

ELFENBEIN DW. (2007), "Patents, publications, and the market for university inventions", Journal of Economic Behavior and Organization, vol. 63, n. 4, pp. 688-715.

ERNST \& YOUNG. (2009). Beyond Borders. Global Biotechnology Report.

GALLINI NT., WRIGHT BD. (1990), "Technology transfer under asymmetric information", RAND Journal of Economics, vol. 21, n. 1, pp. 147-160.

GRANSTRAND O. (1999), The Economics and Management of Intellectual Property, Edward Elgar, Cheltenham.

HALL C. (1991), "Renting ideas", Journal of Business, vol. 64, n. 1, pp. 21-48.

HERATH H.S.B., PARK CS. (1999). "Economic analysis of R\&D projects : an options approach", The Engineering Economist, vol. 44, n. 1, pp. 1-32.

HERNANDEZ-MURILLO R., LLOBET G. (2006), "Patent licensing revisited: heterogeneous firms and product differentiation", International Journal of Industrial Organization, vol. 24, n. 1, pp. 149-175.

JENSEN R., THURSBY M. (2001), "Proofs and prototypes for sale: the licensing of university inventions", American Economic Review, vol. 91, n. 1, pp. 240-259.

KAMIEN MI., TAUMAN Y. (1984), "The private value of a patent: A game theoretic analysis", Journal of Economics, vol. 4, supplement pp. 93-118.

KAMIEN MI., TAUMAN Y. (1986), "Fees versus royalties and the private value of a patent", Quarterly Journal of Economics, vol. 101, n. 3, pp. 471-493.

KAMIEN MI., OREN S., TAUMAN Y. (1992), "Optimal licensing of cost-reducing innovation", Journal of Mathematical Economics, vol. 21, n. 5, pp. 483-508.

KATZ ML., SHAPIRO C. (1985), "On the licensing of innovations”, Rand Journal, vol. 16, n. 4 , pp. $504-520$

KATZ ML., SHAPIRO C. (1986), "How to license intangible property", Quarterly Journal of Economics, vol. 101, n. 3, pp. 567-590.

LAYNE-FARRAR A., LERNER J. (2006), "Valuing patents for licensing: a practical survey of the literature", Working Paper, SSRN: http://ssrn.com/abstract $=1440292$.

LEWIS N., ENKE D., SPURLOCK D. (2004), "Valuation for the strategic management of research and development projects: the deferral option", Engineering Management Journal, vol. 16, n. 4, pp. 36-48.

MACHO-STADLER I., MARTINEZ-GIRALT X., PEREZ-CARSTRILLO JD. (1996), "The role of information in licensing contract design", Research Policy, vol. 25, n. 1, pp. 43-57.

MedAd NEWS. 2000 November.

MILTERSEN KR., SCHWARTZ E. (2004), "R\&D investments with competitive interactions", Review of Finance, vol. 8, n. 3, pp. 355-401. 
PAXSON DA. (2001), "Introduction to real R\&D options", $R \& D$ Management, vol. 31, n. 2, pp. 109-113.

PERLITZ M., PESKE T., SCHRANK R. (1999), "Real options valuation: the new frontier in R\&D project evaluation?", $R \& D$ Management, vol. 29, n. 3, pp. 255-269.

PINDYCK R. (1993), "Investments of uncertain cost", Journal of Financial Economics, vol. 34, n. 1, pp. 53-76.

RAZGAITIS R. (2003), Valuation and Pricing of Technology-Based Intellectual Property, John Wiley \& Sons, New York.

RUBACK RS., KRIEGER DB. (2000), "Merck \& Co.: evaluating a drug licensing opportunity. Case 9-201-023", Harvard Business School Publishing, Boston, MA.

SCHWARTZ E., MOON M. (2000), "Evaluating research and development investments", in Brennan M., Trigeorgis L. Innovation, Infrastructure and Strategic Options, (eds), Oxford University Press, Oxford, pp. 85-106.

SCHWARTZ ES. (2004), "Patents and R\&D as real options", Economic Notes, vol. 33, n. 1, pp. 23-54.

SHAPIRO C. (1985), "Patent licensing and R\&D rivalry", American Economic Review, vol. 75 , n. 2 , pp. 25-30.

SMIT TJ., TRIGEORGIS L. (2004), Strategic Investment, Princeton University Press: Princeton, NJ.

TAYLOR C., SILBERTSON Z. (1973), The Economic Impact of the Patent System: A Study of the British Experience, Cambridge University Press, New York.

THURSBY M., THURSBY J., DECHENEAUX E. (2005), "Shirking, sharing risk, and shelving: the role of university license contracts", Working Paper 11128, National Bureau of Economic Research, Cambridge, MA.

TRIGEORGIS L. (1996), Real Options. Managerial Flexibility and Strategy in Resource Allocation, The MIT Press, Cambridge, MA. 